\title{
A notícia como forma de controle social
}

\author{
Beatriz Marocco e Christa Berger
}

\begin{abstract}
RESUMO
Os jornais fazem da realidade matéria. Acontecimentos e individuos são materializados em figuras que dão conta de objetos parciais, inscritos no seio de uma "realidade" jornalistica. Dois autores nos parecem indispensáveis para pensar em relações entre noticia e controle social. Park e Foucault. Ambos, em diferentes épocas, dedicaram-se ao jornalismo, de forma e intensidade diferentes, quando esse começou a se cristalizar como um dispositivo do modo de vida capitalista. Neste artigo, pretendemos enquadrar o pensamento desses dois autores no sistema do arquivo, que, em seu sentido foucaultiano, possibilita avançar nas relações em rede que as mais diversas teorias que se ocupam do jornalismo nos diferentes umbrais de constituição do pensamento jornalístico podem manter entre si (Foucault, 1995).
\end{abstract}

Palavras-chave: noticia, controle social, arquivo, Park, Foucault

\section{ABSTRACT}

Newspapers turn reality into news. Events and individuals are presented as objects of a "journalistic reality". Two authors are indispensables to think about relations between news and this mode of social control. Park and Foucault. Both, at different moments, worked in different ways and intensities with journalism, when journalism started to crystallize itself as a device of capitalist life. This article is focused on these two authors and the system of the archive. Such background methodology, in its foucaultian sense, makes posible an approximation to Park and Foucault provoking into the archive discoursive relations among what was apparently separeted in the past (Foucault, 1995).

Key words: news, social control, archive, Park, Foucault

* Professora e pesquisadora da Unisinos, Dra. em Jornalismo pela Universidade Autônoma de Barcelona. ** Professora do Programa de Pós-Graduação em Comunicação da Unisinos, Dra. em Comunicação pela USP. 
Michel Foucault não tratou diretamente da notícia, mas deixou pistas sobre a mecânica de controle social que atravessa a produção de figuras discursivas. Mais concretamente, dedicou-se à forma de controle social que caracterizava as instituições disciplinares e em Vigiar e castigar referiu-se à vigilância normalizadora que um tipo de imprensa francesa exercia sobre os corpos dos menos poderosos, quando incluía, obsessiva e diariamente, um "inimigo sem rosto", muito próximo, presente por qualquer lugar e em qualquer lugar perigoso.

Robert Park estudou a notícia diretamente. À semelhança das formas ancestrais de controle social - boatos e falatórios - os jornais norteamericanos, dizia Park, dão testemunho dos acontecimentos, dão relevância aos que se destacam mais e dirigem para eles a atenção do público; salientam o que sai da normalidade, dão o que falar e pretendem preservar uma certa sanidade dos indivíduos, sanidade entendida como a condição de integração na sociedade ou, em outras palavras, notícia e jornal são mecanismos normativos que tenderiam a manter os indivíduos "dominados por um estado de espírito comum, que lhes determina o âmbito e o caráter dos interesses e atitudes ou tendências para agir"'.

As práticas da imprensa porto-alegrense entre o final do século XIX e meados do século XX indicam que os jornais daqui agiam mais ou menos do mesmo modo; jornais como a Gazetinha e a Gazeta da Tarde configuraram certos indivíduos e os combatiam para levantar uma barreira de moralidade 8 entre esses indivíduos "sem importância" e as camadas populares, e entre ambos (pelo viés da pobreza que compartilhavam) e a população em geral (B. Marocco, 2004). Esses discursos oferecem evidências de como se pode apresentar casos de uma atividade desviada a fim de suscitar uma ampla reprovação pública e, em consequêencia, a coesão em torno da norma e da normalização social, mas tal mecânica jornalística não mereceu a devida atenção dos comunicólogos. Neste "substancial ponto cego", reconhecido por Nick Stevenson (1998), a obra de Foucault poderia ter um lugar importante, mesmo tendo se referido pouco ao desenvolvimento histórico dos sistemas de comunicação.

Desde esta lacuna do discurso científico, o desejo de pensar e tratar o jornalismo e os processos jornalísticos históricos, sustentando-se na idéia de que não existe um lugar privilegiado que legitime e objetive o conhecimento sobre algo, encontrará, igualmente, o amplo pensamento de Park. Por diferentes vias, fincados em diferentes épocas, arquiteturas conceptuais e classificações acadêmicas, os dois autores deram conta, isoladamente, do jornalismo e da nova forma de observação e classificação, ora dos acontecimentos, ora dos corpos. $\mathrm{O}$ arquivo foucaultiano oferece condições de possibilidade para aproximá-los. No interior deste outro modo de fazer

'Leia Park, R. "A noticia como forma de conhecimento". 
história, será possível seguir as pistas deixadas ora por Park, ora por Foucault, ora por outros pensadores que estavam, como eles, em busca de explicações para o "fenômeno" do jornalismo ${ }^{2}$ e sua articulação com o capitalismo.

\section{O sistema do arquivo}

Uma figura da caixa de ferramentas foucaultiana permite aproximar esses dois pensamentos aparentemente paralelos. O arquivo. Nos termos do arquivo $^{3}$ foucaultiano, é possível aproximar em um tempo, que não é o seu próprio tempo histórico, diferentes discursos que podem implicar-se uns aos outros. Ao analista caberá desfazer a inércia neste campo, provocar relações entre o que aparentemente estava separado no passado e seguir as pistas de sua emergência repetida e silenciosa, independentemente das circunstâncias formais em que se encontram conservados no presente. Para realizar estas conexões, Foucault esboça a figura do enunciado e a função enunciativa (Foucault, 1995, p. 212-216).

O nível enunciativo, em seu sentido foucaultiano, apoia-se em uma função - a função enunciativa - para formar "unidades abstratas e problemáticas" na extensão de uma curva, imaginada por G. Deleuze, "que une pontos singulares, que efetua ou atualiza relações de força" (1987, p. 108). Deleuze reconhece a complexidade do enunciado em seu sentido foucaultiano a ponto de compará-lo ao sono. Os enunciados de Foucault, disse, são como o sono: cada um tem o seu objeto próprio ou se rodeia de um mundo (1987, p. 34). É necessário segui-los, parece responder-lhe Foucault, ao longo do seu sono, recolher "os temas relacionados ao sono, ao esquecimento, à origem perdida", e procurar "que modo de existência pode caracterizar os enunciados, independentemente de sua enunciação, na espessura do tempo em que subsistem, em que se conservaram" (1995, p. 142). Em outro momento de Foucault, Deleuze define o enunciado como "uma multiplicidade, que atravessa os níveis, que cruza um domínio de estruturas antes de aparecer em formas concretas" (1987, p. 41).

É inútil, disse Foucault, "procurar o enunciado junto aos grupamentos unitários de signos. Nem sintagma, nem regra de construção, nem forma canônica de sucessão e de permutação, mas sim o que faz com que existam tais conjuntos de signos, e permite que essas regras e essas formas se atualizem ". Foucault

\footnotetext{
2 Trata-se das chamadas "Social theories of the press" (H. Hardt, 1979).

${ }^{3}$ As relações enunciativas materializam o "sistema de funcionamento" do arquivo que permite que os enunciados subsistam e se modifiquem regularmente. Assim, o arquivo é tanto o lugar do que pôde ser dito, como o nivel particular das práticas discursivas dos saberes e das instituições que, no presente, vai possibilitar a atualização dos discursos do passado como práticas especificadas.
} 
segue descrevendo os enunciados com uma série de negações. Não são como o ar que respiramos. Não são transparentes, são raros. Não estão escondidos, o que não significa que sejam visiveis. Não estão habitados pela presença secreta do que não foi dito, das significações ocultas. Não são o mesmo que o "reprimido". Não se oferecem à percepção; é preciso certa mudança no olhar e na atitude para poder reconhecê-los e considerá-los em si mesmos (1995, p. 100).

Foucault não quis aprisionar o enunciado e suas regras de aparição e existência em uma noção, como se esse pudesse ser ao mesmo tempo uma trađução precária e pletórica de um elemento conceptual que o transcende; definiu-o como uma "função enunciativa", talvez do mesmo modo que $M$. Bakhtin", "ligado não apenas a situações que o provocam e a conseqüências por ele ocasionadas, mas, ao mesmo tempo, e segundo uma modalidade inteiramente diferente, a enunciados que o precedem e o seguem", nos diferentes grupos de discursos onde funciona (1995, p. 32).

Tal dinâmica conecta simultaneamente a existência de um enunciado a um discurso, ao saber a que pertence e a uma rede aberta e interligada de diferentes discursos, que nos permite identificá-lo imediatamente como elemento de um sistema com certo grau de organização, independentemente de seu autor ou de quando foi pronunciado. Ao invés de recolher as familiaridades gramaticais quase perceptivas entre as palavras e as coisas, 0 enunciado pode estabelecer relações entre as coisas ditas.

\section{Coesão e coação social}

Desde uma perspectiva foucaultiana poder-se-ia situar o jornalismo, na virada do século passado, no âmbito de uma teoria da dominação e dos efeitos no discurso, como um dispositivo de sujeição dos corpos e daí avançar na idéia de notícia como um instrumento de exclusão social, graças à objetivação da periculosidade de certos indivíduos e das estratégias conjuntas, adotadas entre o jornalismo e outras instituições, para controlálos. A notícia insinua-se, neste quadro, como um instrumento de controle social que pode gerar a coesão social em torno da norma (que marginaliza o outro infrator) ou dar conta dos procedimentos técnicos de coação dos corpos dos mais perigosos, incluindo-os no discurso para visibilizar a sua exclusão da sociedade. Neste duplo sentido, isso é, de coesão dos indivíduos em

\footnotetext{
4 Para Bakhtin, um enunciado supõe uma cadeia de enunciados, à medida em que sempre supõe outros enunciados que o precederam e que lhe sucederão em uma relaçăo que não se pode definir por termos de categorias mecânicas ou lingüísticas: "Um enunciado sempre supõe que o precederam e que lhe sucederão; ele nunca é o primeiro nem oúltimo; é apenas o elo de uma cadeia e não pode ser estudado fora desta cadela. Existe uma relação entre os enunciados impossível de definir por termos de categorias mecânicas ou linguísticas" (1992, p. 375).
} 
torno da norma e das limitações coercitivas dos corpos sob as técnicas disciplinares, executadas por uma rede de instituições, poder-se-ia explicar a ordem social.

A concepção parkiana de controle social está situada no âmbito de uma teoria do jornalismo e dos efeitos da notícia: dá consistência à mecânica de coação social que se instala na notícia dessa mesma época e aos efeitos que produz, não em termos de corpos, mas sim no seio do público, em termos de opinião pública, e que dependeria de uma instituição singular de observação e classificação das coisas que passam na realidade (o jornalismo). Jornal e notícia vão fazer funcionar um tipo de coação no jogo comunicacional na cidade grande, onde os indivíduos não estariam mais em condições de controlar as suas mensagens. A notícia, na metrópole, teria como função organizar os rumores que, nas comunidades primitivas, eram passados de boca em boca, controlá-los dando-lhes repercussão e uma amplitude geográfica. Na visão de Park, a notícia seria algo que, como nas comunidades primitivas, coage as pessoas para que essas tentem se adequar às normas e às formas convencionais para que assim se dissipem os rumores e não se fale mais delas.

\section{Noticia e controle social em Foucault}

As pistas deixadas por Foucault em Vigiar e punir sobre o controle que um tipo de imprensa francesa exerce sobre os corpos dos menos poderosos, quando inclui, obsessiva e diariamente, um "inimigo sem rosto", muito próximo, presente por qualquer lugar e em qualquer lugar perigoso, assim como as práticas jornalísticas da imprensa porto-alegrense, nos indicaram que ambas configuraram a alteridade e a combatiam para levantar uma barreira de moralidade entre os indivíduos "sem importância" e as camadas populares, e entre ambos (pelo viés da pobreza que compartilhavam) e a população em geral e que, ainda, pretendiam dividi-los no interior de si mesmos.

Esse modo de objetivação jornalística, como vimos em trabalho anterior (Marocco, 2004) fez a notícia funcionar como uma forma e uma prática de mediação simbólica que simultaneamente revela e oculta as operações do poder e abriga práticas disciplinares específicas para apresentar os indivíduos e produzir efeitos de verdade. Como vimos anteriormente, através da crônica policial (os jornais franceses) ou da nota jornalística, os jornais apresentaram figuras em suas relações promíscuas e perigosas em uma manobra que dava vazão à "anormalidade", suspendia a subjetividade, e que transformou o corpo desses individuos em vetor de técnicas que combinam a hierarquia de quem observa a um julgamento normalizador. Uma mirada normalizadora que possibilita classificar, qualificar e sugerir um castigo. Discursos que pretendiam a normalização das condutas na sociedade, e, por fim, o controle social.

Como se fossem matéria que se pode estender ou contrair mecanicamente, os corpos eram manipulados, modificados, reduzidos e ajustados ao diagrama jornalístico, em operações que lhes atribuiam um discurso verdadeiro para corrigir as suas deformidades - uma espécie de 
ortopedia discursiva. Em outras palavras, poder-se-ia dizer que a passagem de indivíduo imoral a sujeito de um discurso jornalístico, naquelas condições históricas, era resultado de um modo de objetivação jornalística ${ }^{5}$ que fazia funcionar duas operações complementares.

Em uma primeira operação, os corpos eram ajustados à sua nova forma de seres-linguagem em um espaço loteado em colunas e limitado por uma linha invisível que, desde a parte mais elevada até a sua base, indicava a página, através de grafismos fixos, como o grande signo da materialidade jornalística. $\mathrm{O}$ ajuste dos corpos à página era realizado em dois movimentos simultâneos: 1. Constrição. No movimento de constrição, o que pertencia à realidade era fragmentado em milhares de notas jornalísticas e 2 . Construção.

No movimento de construção, os seres humanos eram transformados em seres-linguagem, segundo condições jornalísticas de espaço e tempo, no interior de notas impregnadas por uma maneira regular de observar e apresentar a realidade do jornalista decimonônico. Nos dois movimentos, assim como no "olhar normalizador" do "exame" comprometido com a intenção de enfocar certas pessoas e tornar transparentes os comportamentos virtualmente "perigosos" para salientá-los entre a população em geral e combatê-los. Essa visibilidade transformará o indivíduo em um "espetáculo" público, aberto à inspeção, à observação e à interrogação. Chamaremos a esta operação de ajuste à página, "ductilidade dos corpos".

Em uma segunda operação, os jornais apresentavam uma nova cidade nos mapas da "periculosidade" que eram desenhados sobre a cartografia original e que pretendiam, em conjunto com o governo e uma rede de instituições, uma intervenção orquestrada na capacidade dos corpos de movimentarem-se em liberdade. A este tipo de operação, que deu vazão a discursos associados ao projeto do governo brasileiro de "repressão à ociosidade" e às "profissões desonestas" e que

\footnotetext{
${ }^{5}$ Foucault reconhece três modos de objetivação que transformam os seres humanos em sujeitos: "Quisiera decir en primer lugar cuál ha sido la finalidad de mi trabajo durante estos últimos veinte años. No há sido analizar los fenómenos de poder, ni sentar las basis para tal análisis. Busco más bien producir una historia de los diferentes modos de subjetivación de los seres humanos en nuestra cultura; he tratado, desde esta óptica, de los tres modos de objetivación que transforman los seres humanos en sujetos. Primeramente, están los diferentes modos de investigación que buscan acceder al estatuto de ciencia: pienso, por exemplo, en la objetivación del sujeto que habla en la gramática geral, filología y lingüística. 0 bien, y siempre en este primer modo, la objetivación del sujeto productivo, del sujeto que trabaja, en la economía y el análisis de riquezas. O también, para dar un tercer ejemplo, la objetivación por el mero hecho de ser un ser vivo, en historia natural o biología. En la segunda parte de mi trabalho, he estudiado la objetivación del sujeto en lo que llamaré las prácticas escindientes [pratiques divisantes]. Finalmente, he buscado estudiar —y éste es mi trabalho en curso-el modo en el que el ser humano ha aprendido a reconocerse como sujeto de una sexualidad" (Foucault, 1990, p. 6.20-21).

${ }^{6} \mathrm{O}$ "exame", segundo Foucault, "es una mirada normalizadora, una vigilancia que permite calificar, clasificar y castigar. Establece sobre los individuos una visibilidad a través de la cual se los diferencia y se los sanciona"-(Foucault. 1986 p.+ 189). P.P. Velamazán aproximará ainda mais o "exame" das práticas jornalísticas de observação ao afirmar que "la técnica del examen (grifo do autor) hace entrar la singularidad de los individuos en un campo documental, una red de escritura, a la vez que los coloca en un campo de vigilancia" (Velamazan, 2000, p. 189).
} 
evidencia a coerção ininterupta e constante que o jornalismo podia exercer sobre os deslocamentos e a orientação correta dos seres a partir da página e em seu prolongamento na sociedade, chamaremos "docilidade dos corpos".

\section{Notícia e controle social em Park}

Em diferentes momentos, ao longo de sua obra, Park dá conta da noticia em sua dupla face: como uma "forma elementar de conhecimento" e como um dispositivo de controle social. Comte já havia anunciado o quão eficaz poderia ser essa mistura; breve, disse ele, os governos vão se dar conta do quanto a "propagação universal dos conhecimentos reais" da imprensa, do drama e das novelas poderá auxiliar na difícil tarefa de manutenção de una "ordem indispensável":

Los gobiemos actuales advertirán pronto de cuánta eficacia puede ser la propagación universal de los conocimientos reales, para secundar sus esfuerzos continuos por el dificil mantenimiento de un orden indispensable (1934, p. 182).

Apesar das diferentes abordagens, Park aproxima-se de Foucault e de Comte nessa tese, ou seja, para os três há uma estreita cumplicidade entre poder e produção de saber. E a notícia/discurso será a conjunção de um e outro, a forma através da qual o poder opera; tem um caráter produtivo e um alcance político, perpassa as coisas, mete-se na pele dos individuos, invadindo os seus gestos, as suas atitudes, os seus discursos, suas experiências, enfim, a vida cotidiana.

Park vai avançar desse ponto em direção aos efeitos no âmbito da notícia e das relações sociais; com isso dará visibilidade, ao longo de sua obra, à influência da noticia sobre o individuo e a opinião pública, distanciando-se tanto de Foucault quanto de Comte na medida que, para ele, o jornalismo, nesta função reguladora, não se transforma num dispositivo para seqüestrar, controlar os corpos dos menos poderosos e construir figuras no discurso (Foucault) nem em um parceiro incondicional dos governos para a educação popular (Comte).

O jornal, na concepção parkiana, é um organismo vivo imerso em um processo contínuo de adaptação às necessidades sociais dos individuos e dos grupos. Um organismo que entra em simbiose com os grandes centros urbanos para regular as condutas e exercer uma "extensão da função de controle social que era exercida espontaneamente, em outras condições históricas, pela comunidade, através do contato pessoal e dos boatos" (Park,

\footnotetext{
${ }^{7}$ As cidades brasileiras estavam transbordando ex-escravos, mas a maioria deles era pouco capacitada para as fábricas e estas preferiam os imigrantes. A presença numerosa de ex-escravos livres, além disso, gerava discursos inquietantes sobre o "outro" perigoso, dificilmente controlável. Na confluéncia destes elementos, o governo brasileiro lançou o projeto de "repressão à ociosidade" em que definiu uma estratégia politica com o objetivo de vincular uma massa de individuos ao novo estatus jurídico do "trabalho em liberdade" e a uma nova ética que o concebia como algo positivo; algo "civilizado" e "civilizador", como o "bem supremo", que já não era "coisa de escravos". O projeto foi apresentado pelo ministro Ferreira Viana à Câmara dos Deputados do Brasil, dia 19 de julho de 1888 .
} 
1923, p. 278). Essa mecânica jornalística de controle no sentido parkiano materializa-se na notícia e supõe dois procedimentos técnicos:

1. Os jornais definem uma certa ordem de preferências temáticas, desempenhando o que Park chamou "a função indicadora das notícias". $\mathrm{O}$ que Park quer dizer com isso é que a notícia se esforça para capturar a mente do público e dirigir a sua atenção para determinados acontecimentos relacionados com o insólito e o inesperado:

... limita-se caracteristicamente, se não sempre, a acontecimentos que produzem mudanças súbitas e decisivas; pode ser um incidente, como o da família de cor em Filadélfia, Frances e Bem Mason, que ganhou recentemente uma fortuna na loteria da Irlanda; pode ser um trágico incidente, como a batalha ao largo das costas do Uruguai, que resultou na destruição do navio de guerra alemão Graf Spee; e no suicídio do seu comandante (Park, 1940, p. 179-180).

Em "Social Decadence", artigo publicado em 1918, E. Ross já havia sugerido que o "grande e crescente poder sobre o público" acontecia porque os jornais noticiavam um tipo de fato, mantinham versões na clandestinidade, alçavam o que queriam à primeira página e com a relevância determinada por seu dono. Ou seja, o dono do jornal fazia a opinião pública sem que o público soubesse disso.

2. Os jornais salientam o que sai da normalidade e, para que não se fale delas, ou para dissipar os rumores, as pessoas tentam adequar-se às normas (Park, 1923, p. 278, 289; B. Conde, 2000, p. 236). Na medida que o consegue, diz Park, o jornal tende a preservar a sanidade do indivíduo e a permanência da ordem na sociedade (Park, 1940, p. 183).

Do ponto de vista do processo cognitivo gerado pelas notícias, Park dirá que o indivíduo será afetado em maior ou menor grau dependendo das distâncias geográficas, temporais ou psíquicas que o separam das notícias. Quanto mais distante do ponto em que se originou a notícia, mais o indivíduo estará alheio a essa realidade produzida. O impacto que a notícia anuncia terá pouca influência sobre a sua vida (B. Conde, 2000, p. 271). Por outro lado, muito mais do que informar o público, as notícias tendem a orientá-lo, à semelhança do que ocorre com a percepção a nível individual. Cada indivíduo interpretará a notícia, de acordo com os seus próprios interesses, preconceitos e predileções, dando seqüência a um jogo comunicativo com a interpretação alheia da mesma notícia. O choque de opiniões que a discussão

${ }^{a}$ M. McCombs e D. Evatt situam esta função na origem da agenda-setting embora atribuam a Lippmann o fundamento intelectual da mesma, o que, na opinião de B. Conde, deve-se à precária divulgação da obra de Park. "En mi opinión, diz ela, a Park sólo se le menciona tímidamente como precursor de esta teoría porque su obra es muy poco conocida. De ahí que las referencias a su aportación intelectual en este contexto sean, cuando existen, muy breves y carezcan totalmente de justificación. La alusión y explicación de las contribuciones de Lippmann, cuya obra há sido más difundida, es, sin embargo, mucho más amplia" (B. Conde, 2000, p. 270).

${ }^{9}$ Ross, segundo Park, introduziu e popularizou o estudo do "controle social' na sociologia, em 1901, através da obra Social control, a survey of the foundations of order (B. Conde, 2000, p. 156). Em 1910, no artigo "The suppression of important news", ele voltou-se ao jornalismo criticando a subordinação dos jornais ao capital e a desinformação que podem gerar quando se transformam em instrumento para difundir certo tipo de noticia (1994, p. 194). 
invariavelmente provoca, terminará numa espécie de consenso ou opinião coletiva, "opinião pública". Nestes termos, as notícias auxiliam as pessoas a interpretar os acontecimentos e não exigem do repórter nenhum esforço, "exceto o esforço para torná-los compreensiveis e interessantes". Park fala, igualmente, na relação que a notícia deve manter com os preconceitos locais e as limitações do público:

Um exame mais acurado dos fatos revelaria, muito possivelmente, a um espirito mais critico e esclarecido, a ingênua credulidade e parcialidade de uma opinião pública não sofisticada. Com efeito, a ingenuidade e a credulice assim reveladas podem tornar-se importante dado histórico ou sociológico. Isso, contudo, serve apenas para ilustrar o fato de que todo publico tem seu próprio universo de discurso e de que, humanamente falando, um fato só é fato em algum universo de discurso (1940, p. 178).

Em parte, Park dialoga com Lippmann quando esse afirma que o indivíduo define o mundo ao seu redor de acordo com estereótipos já presentes em sua mente. Em parte se distancia de Lippmann; quando Lippmann critica o potencial de manipulação da imprensa, Park vai ser mais otimista concebendo, como vimos anteriormente, o ideal da objetividade das notícias e a cisão entre informação de opinião. No entanto, o mesmo Park confessaria que o seu desejo foi o de exercer o jornalismo como uma forma de "moldar a opinião pública", reconheceria que o jornalista urbano cumpria, nessa época, o papel de um sociólogo informal e intuitivo, que atuava como o censor moral de uma audiência que estava muito dispersa e sobre a qual já não era mais possível controlar diretamente, e, finalmente, diria, em 1923, que o jornalista deveria aprender a olhar a vida social e politica de uma maneira objetiva e deixar de pensar somente em termos morais (B. Conde, 2000, p. 6; Park, 1923, p. 289).

\section{Considerações finais}

Nas condições históricas da sociedade moderna, o trabalho e a disciplina dominaram tanto a fábrica como as instituições - pedagógicas, médicas, penais e industriais - que vão se encarregar da vida dos indivíduos (Z. Bauman, 1999; Foucault, 1998). Milhares de discursos sobre a superioridade moral de qualquer tipo de vida (não importava o miserável que fosse), que se sustentasse com o salário do próprio trabalho, foram produzidos. 
As tendências "moralmente" vergonhosas das profissões desonestas, por outro lado, foram condenadas. $O$ trabalho fixou uma ética e, com ela, as pautas de uma conduta correta. Um manto de suspeita foi lançado sobre todo aquele que não se submetesse à disciplina da fábrica.

Benjamin incluiu o jornalismo nesta cena. Enquanto o efeito da tecnologia sobre o trabalho e sobre o ócio havia sido dividir a experiência em fragmentos, o estilo jornalístico, disse ele, refletiu a fragmentação nas "transitórias imagens materiais" do que produzia, montava e irradiava em uma montagem (Benjamin, citado em S. Buck-Morss, 1995: 40-41).

A fascinação que essa cena do passado exerceu sobre Benjamin, Foucault e, mais recentemente, Bauman, entre outros autores, é inegável. Foucault explicou-a através da sociedade disciplinar. Park não teve o distanciamento histórico de Foucault. Foi um elemento ativo da mesma cena: trabalhou como repórter e fez eco do pensamento social de seu tempo, materializando evidências de que a sua teoria coincide, aproximadamente, com as práticas que se davam nos jornais modernos, embora entre uns e outros não pareça existir a mais mínima relação de dependência. Entretanto, com o que disse sobre o jornal e a notícia, Park acaba dando espessura a algumas lacunas epistemológicas do pensamento foucaultiano, aproximandoo do jornalismo - afinal, Foucault mais sugeriu do que disse algo concreto sobre o jornalismo.

Nesta estranha convivência, foi possível tecer uma rede alinhavando 16 enunciados que de outro modo permaneceriam isolados em suas diferenças formais, para poder avançar na compreensão da constituição da notícia como uma forma de controle social. E, com isso, avançar em três temas: as práticas, a que tanto Foucault como Park se dedicaram, a estreita dependência que se formalizou naquele momento com o estado e uma rede de instituições que se ocupam de seqüestrar o corpo, o tempo e o espaço dos individuos, e que essas formalizaram, e no desenvolvimento de uma metodologia adaptada às particularidades do jornalismo e que possibilita, igualmente, compreendê-lo em diferentes momentos de sua constituição.

Recentemente, E. Machado reconheceu que as práticas profissionais estão sendo muito mal inventariadas nas pesquisas realizadas no Brasil e que um pesquisador que esteja interessado em descobrir as especificidades do jornalismo deve preocupar-se, antes de mais nada, em viabilizar a criação de metodologias de pesquisa ou de ensino adaptadas às particularidades do jornalismo (2004, p. 5, 10). Acreditamos que qualquer movimento nesse sentido, que esteja afinado com a necessidade de consolidação do jornalismo como campo do conhecimento não pode prescindir de um terceiro movimento: o de buscar preencher as lacunas epistemológicas de um passado mal contado, principalmente nesse estreito período de tempo em que alguns conceitos centrais para o jornalismo, a objetividade, por exemplo, emergiram de epistemes exógenas. 


\section{Referências}

BAKHTIN, M. 1992. Estética da criação verbal. São Paulo, Martins Fontes. BAUMANN, Z. 2000. Trabajo, consumismo y nuevos pobres. Barcelona, Gedisa.

BUCK-MORSS, S. 1995. Dialéctica de la mirada. Walter Benjamin y el proyecto de los Pasajes. Madrid, La balsa de la Medusa.

FOUCAULT, M. 1993. Microfisica do poder. Rio de Janeiro, Graal, $11^{\mathrm{a}}$ edição. FOUCAULT, M. 2000. Vigiar e punir. Petrópolis, Vozes, $12^{a}$ edición.

FOUCAULT, M. 1995. Arqueologia do saber. Rio de Janeiro, Forense Universitária, $4^{a}$ edição.

FOUCAULT, M. 1990. Tecnologias del yo y otros textos afines. Barcelona, Paidós/ICE-UAB.

FOUCAULT, M. 1998. Laverdad y las formas juridicas. Barcelona, Gedisa, $4^{\mathrm{a}}$ reimpresión.

HARDT, H. 1979. Social theories of the press. Early german \& american perspectives. Sage Publications, Inc., Beverly Hills, 239p.

MACHADO, E. "Dos estudos sobre o jornalismo às teorias do jornalismo". E-compós, 2004/01.p. 1-15.

MAROCCO, B. 2004. Prostitutas, jogadores, pobres e vagabundos no discurso jornalístico. Editora Unisinos, São Leopoldo.

PARK, R. "A noticia como uma forma de conhecimento". Em STEINBERG, C. [org.] 1970. Meios de Comunicação de massa. São Paulo, Cultrix, p. 168-185.

PARK, R. "News and the power of the press". The American Journal of Sociology, vol. XLVIl, jul. 1941, n. 1, p. 1-11.

PARK, R. "The natural history of the newspaper". The American Journal of Sociology, vol. XXIX, nov. 1923, n. 3, p. 273-289.

ROSS, E. A. "La supresión de las noticias importantes". REIS, 94/01, p. 191202.

STEVENSON, N. 1998. Culturas mediáticas. Buenos Aires, Amorrortu editores. 
Gontracamin 